\title{
PM SOURCE APPORTIONMENT ANALYSIS IN THE VENETIAN AREA
}

\author{
Silvia Pillon ${ }^{1}$, Fabio Dalan ${ }^{1}$, Francesca Liguori ${ }^{l}$ and Giuseppe Maffeis ${ }^{2}$ \\ ${ }^{1}$ Regional Environmental Protection Agency of the Veneto Region (ARPAV) Air Observatory, Venice Italy \\ ${ }^{2}$ Terraria s.r.l., Milan Italy
}

\begin{abstract}
A multi-scenario approach is applied on a CALMET-CAMx System to investigate particular matter $\left(\mathrm{PM}_{10}\right)$ source apportionment on the wide urban area of Venice and its mainland. The baseline scenarios is verified against measurements of PM $\mathrm{P}_{10}$ and chemical speciation of the filters. A nested grid structure is used to separate local contributions to PM10 concentration levels of the different emission sectors from those of middle and long range transports.
\end{abstract}

Key words: PM10, source apportionment, brute-force method.

\section{INTRODUCTION}

A useful application of a photochemical modelling system is the assessment of the potential effectiveness of pollutant emissions control strategies.

Chemical transport models (CTMs) provide a useful platform for studying the source contributions to both secondary and primary pollutant concentrations because they explicitly simulate the atmospheric processes: emissions, transport, removal, chemistry, and aerosol physics.

A study has been performed to evaluate the relative role of different sources in the production of $\mathrm{PM}_{10}$ in the Venetian area both through measurements and chemical speciation (Biancotto et al., 2007) and through a modelling exercise (Pillon et at., 2007) by the Regional Environmental Protection Agency of Veneto for two winter months in the year 2006 .

\section{MODELLING SYSTEM SETUP AND EVALUATION}

A multi-scenario approach is applied on a CALMET-CAMx System (Benassi et al., 2007; Dalan et al., 2005) to investigate fine particular matter $\left(\mathrm{PM}_{10}\right)$ source apportionment on the wide urban area of Venice and its mainland. A nested grid is used to separate local contributions to $\mathrm{PM}_{10}$ concentration levels of the different emission sectors from those of middle and long range transports.

CALMET model (Scire et al., 2000) is used to produce the meteorological fields and CAMx (ENVIRON International Corporation, $2004 \mathrm{v} 4.03$ ) is applied for the dispersion of primary and secondary aerosols. The 200x168 $\mathrm{km}^{2}$ domain covers most of the Veneto region on a $4 \times 4 \mathrm{~km}^{2}$ resolution mesh while a $1 \mathrm{~km}$ nested grid is used over Venice and its suburbs. Emissions of an integrated Bottom-Up and Top-Down inventory (Gnocchi et al., 2005; Gnocchi et al., 2006) are distributed over the domain according to the land use, while the major point sources emit at the stack height and they are modelled with a Lagrangian approach (CAMx plume-in grid tool).

The modelling system has been run for February and March 2006. The concentration fields of $\mathrm{PM}_{10}$ and its organic and inorganic components have been computed and compared with daily measurements taken in 4 different sites: two urban sites - one at a curb-side of a busy state street, near a traffic light in a mid-size town surrounded by the countryside and one within the urban area of Mestre, the mainland town of Venice - a rural background site and an industrial site.

The model performs the best in the industrial site and the worst at the urban curb-side as the exposure to road transport emissions can not be properly described by an Eulerian model with $1 \times 1 \mathrm{~km}^{2}$ resolution mesh. Pearson's coefficients between measured and modelled $\mathrm{PM}_{10}$ concentrations calculated for each site lay between 0.8 and 0.9 . Daily mean $\mathrm{PM}_{10}$ concentrations are well reproduced by the model on pristine days (24/02 and 11/03 in Figure 1), whereas the model underestimates the measurements when stagnant air conditions persists for several days. A fine resolution run (nest-grid output $-1 \times 1 \mathrm{~km}^{2}$ resolution) improves the model estimate compared to a coarse grid one (master grid output $-4 \times 4 \mathrm{~km}^{2}$ resolution). 


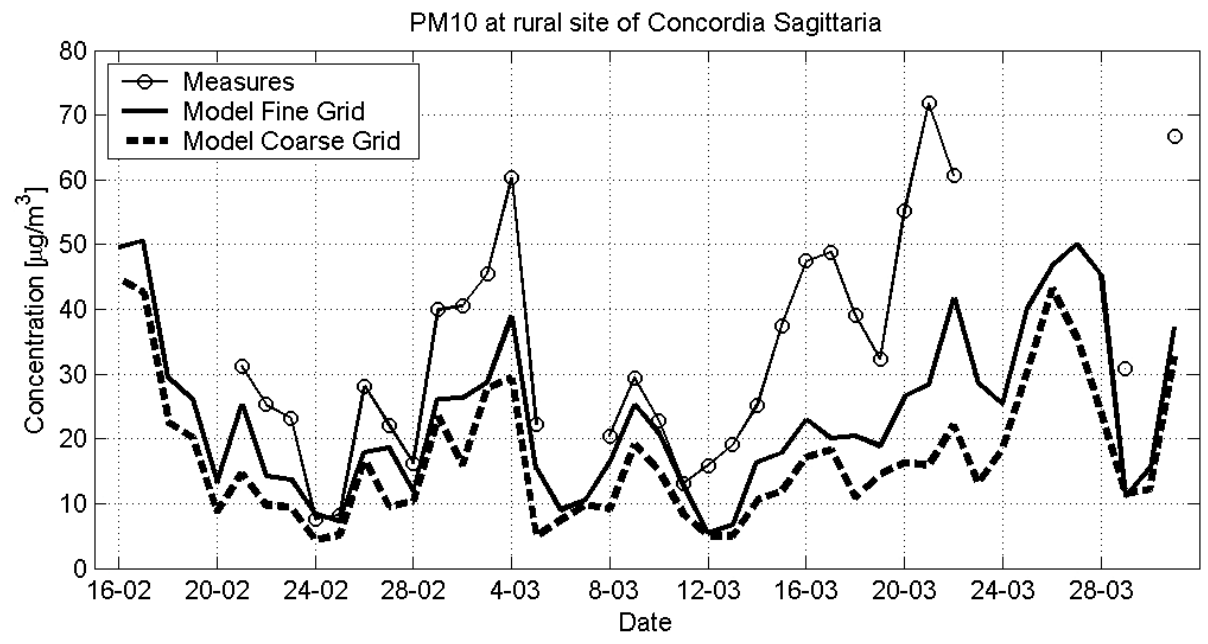

Figure 1. Comparison of experimental data with nest-grid and master-grid model outputs for he rural site.

In figure 2 measured and modelled $\mathrm{PM}_{10}$ components are presented for the rural site from the $24^{\text {th }}$ of February (low $\mathrm{PM}_{10}$ pollution thanks to a thunderstorm) till the $4^{\text {th }}$ of March (high $\mathrm{PM}_{10}$ build-up concentrations before next thunderstorm arrival). Only the PM10 components presents both in the measurements and in the model outputs are shown, i.e. nitrate $\left(\mathrm{NO}_{3}\right)$, sulphate $\left(\mathrm{SO}_{4}\right)$, ammonium $\left(\mathrm{NH}_{4}\right)$ and total primary and organic carbon (Ctot). The model is able to reproduce the inorganic aerosols growth (especially $\mathrm{NH}_{4}$ and $\mathrm{NO}_{3}$, whereas for $\mathrm{SO}_{4}$ there is slighty underestimated), but cannot capture the growth of the total carbon component.
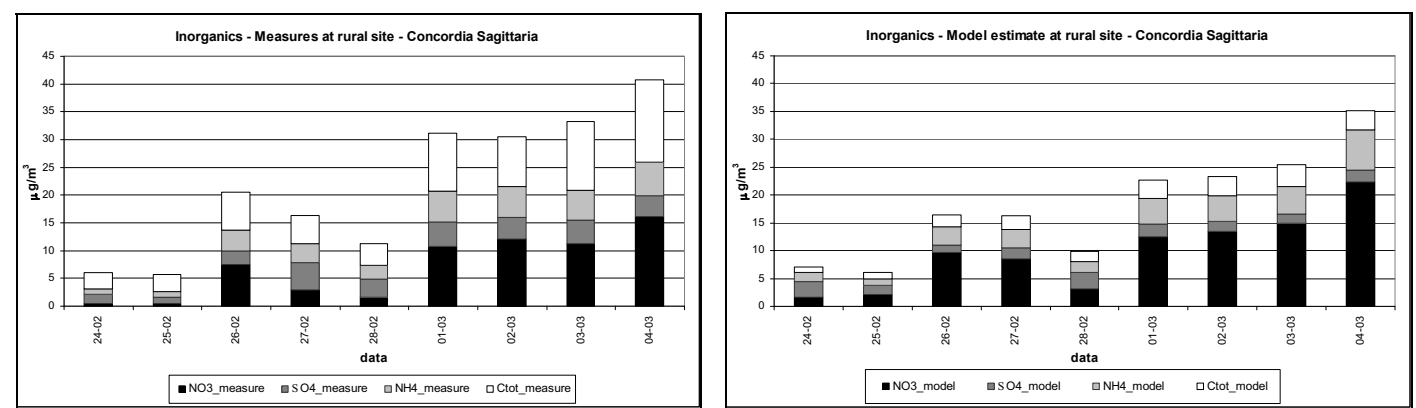

Figure 2. Measured (left) and modelled (right) PM10 components for the rural site. NO3 in black, SO4 in dark grey, NH3 in light grey and total primary and organic carbon in white.

The contribution of different emission sectors to $\mathrm{PM}_{10}$ concentrations has been estimated through five scenarios runs with a 50\% emission reduction for each of the following sectors: road transport (scenario 1), industrial plants (scenario 2), other transports - airport, port and off road transports (scenario 3), domestic heating (scenario 4) and agriculture (scenario 5). The reductions have been applied only on the nested grid in order to separate local contributions (generated in the nested area) from middle and long range pollution transports.

In this "brute-force" method (Wagstrom K. M. et al., 2008), the impact of different sources is quantified by perturbing emission input source-by-source and calculating the changes in pollutant concentrations resulting from the perturbation. The 50\% reduction scenarios have been undertaken in order to minimize non-linear effect that may arise due to drastic changes in atmospheric composition and reactivity. In later versions of CAMx, not yet available at the time this study was performed, a Particulate Matter Source Apportionment Technology (PSAT) has been implemented. The PSAT methodology is able to calculate the impact of several sources in a single run accounting also for the non-linearity of the chemical reactions.

The emission reductions of each scenario, relative to the total emissions in the whole domain and in the nested area, is reported in Table 1. 
Table 1. Relative emission variations of each scenario with respect to the baseline.

\begin{tabular}{|l|r|r|r|r|r|r|r|r|}
\hline Domain & \multicolumn{1}{|c|}{ Whole } & \multicolumn{1}{c|}{ Nest } & \multicolumn{1}{c|}{ Whole } & \multicolumn{1}{c|}{ Nest } & \multicolumn{1}{l|}{ Whole } & Nest & \multicolumn{1}{c|}{ Whole } & \multicolumn{2}{|c|}{ Nest } \\
\hline Scenarios & \multicolumn{2}{|c|}{$\mathrm{PM}_{10}$} & \multicolumn{2}{|c|}{$\mathrm{NO}_{\mathrm{x}}$} & \multicolumn{2}{|c|}{$\mathrm{SO}_{2}$} & \multicolumn{2}{|c|}{$\mathrm{NH}_{3}$} \\
\hline 1. Road Transports & $-4.3 \%$ & $-14.5 \%$ & $-7.6 \%$ & $-19.5 \%$ & $-0.3 \%$ & $-0.7 \%$ & $-0.5 \%$ & $-1.6 \%$ \\
\hline 2. Industrial Plants & $-4.8 \%$ & $-16.0 \%$ & $-6.8 \%$ & $-17.5 \%$ & $-14.9 \%$ & $-41.3 \%$ & $-1.8 \%$ & $-5.8 \%$ \\
\hline 3. Other Transports & $-2.3 \%$ & $-7.9 \%$ & $-2.7 \%$ & $-6.8 \%$ & $-1.8 \%$ & $-5.0 \%$ & $0.0 \%$ & $0.0 \%$ \\
\hline 4. Domestic Heating & $-3.0 \%$ & $-9.9 \%$ & $-2.3 \%$ & $-6.0 \%$ & $-0.9 \%$ & $-2.5 \%$ & $0.0 \%$ & $0.0 \%$ \\
\hline 5. Agriculture & $0.0 \%$ & $0.0 \%$ & $0.0 \%$ & $0.0 \%$ & $0.0 \%$ & $0.0 \%$ & $-12.6 \%$ & $-41.9 \%$ \\
\hline
\end{tabular}

\section{RESULTS}

Scenario runs led to two results:

1. an estimation of local emission contribution to $\mathrm{PM}_{10}$ concentrations. In the hypothesis that the emission perturbations had not changed significantly the atmospheric composition and reactivity, the local anthropogenic emission contribution to $\mathrm{PM}_{10}$ levels has been calculated as twice the sum of the different emission sector contributions (since the scenario reductions applied were $50 \%$ of the sector's emission and the five scenarios together include all anthropogenic sources);

2. source apportionment of the different emission sectors to the locally produced $\mathrm{PM}_{10}$. The main purpose of the scenario approach was to track the source contributions to $\mathrm{PM}_{10}$ concentrations, at least for the primary and the secondary inorganic $\mathrm{PM}_{10}$ components for which the modelling system shows an acceptable level of confidence.

As far as the first result is concerned, CAMx model estimate a local contribution to the $\mathrm{PM}_{10}$ levels from a minimum value of $30 \%$ to a maximum of $50 \%$ depending on the site (Tab. 2). The local contribution is minimum when anthropogenic emissions are the lowest, hence in the rural site.

Local contributions, divided in the different PM10 components (nitrate, sulphate, ammonium, organic carbon and residual inert primary fraction) for the 4 sites under investigation are shown in Table 2 . The local contribution of $\mathrm{NO} 3$ to the total $\mathrm{PM}_{10}$, for example, has been estimated using the following formula:

2*(delta_NO3_sc1 + delta_NO3_sc2 + delta_NO3_sc3 + delta_NO3_sc4 + delta_NO3_sc5)/(PM10_baseline $)$

where delta_NO3_scN is the difference between the $\mathrm{NO}_{3}$ in the Nth scenario and the NO3 in the baseline run. The factor 2 is applied to account for the $50 \%$ reduction of the scenario emissions instead of the $100 \%$ reduction.

Table 2. Local contribution with chemical speciation for the 4 sites under investigation.

\begin{tabular}{|l|r|r|r|r|r|r|}
\hline Site & Nitrate & Sulphate & Ammonium & Organic Carbon & $\begin{array}{l}\text { Other Primary } \\
\text { Fraction }\end{array}$ & $\begin{array}{l}\mathrm{PM}_{10}-L^{2} \\
\text { Contribution }\end{array}$ \\
\hline Rural background & $-15 \%$ & $-1 \%$ & $-5 \%$ & $-4 \%$ & $-2 \%$ & $-27 \%$ \\
\hline Urban curb-side & $-9 \%$ & $-3 \%$ & $-4 \%$ & $-10 \%$ & $-8 \%$ & $-35 \%$ \\
\hline Urban & $-8 \%$ & $-4 \%$ & $-4 \%$ & $-15 \%$ & $-14 \%$ & $-45 \%$ \\
\hline Industrial & $-8 \%$ & $-4 \%$ & $-4 \%$ & $-15 \%$ & $-17 \%$ & $-48 \%$ \\
\hline
\end{tabular}

In the rural site, where $\mathrm{NO}_{\mathrm{x}}$ and $\mathrm{NH}_{3}$ emissions are predominant in respect to primary $\mathrm{PM}_{10}$, local $\mathrm{PM}_{10}$ is mainly made of nitrate; in the urban and the industrial sites organic carbon and primary fraction are more relevant.

The two-month run of winter 2006 assesses that local contribution to $\mathrm{PM}_{10}$ is less than the trans-boundary transport. Due to the orography of Northern Italy the trans-boundary PM pollution is thought to arrive mainly from the Po Valley basin, hence from the Veneto region outside the Venetian area and from the neighbour northern Italian regions. The reduction in concentrations due to the different scenarios is localized almost entirely inside the area in which emission reductions are applied (nested domain) and it extends only slightly outside such area, along the prevalent wind direction (Fig. 3).

An example of the average scenario reduction is outlined in figure 3: the left panel presents the absolute differences in $\mu \mathrm{gm}^{-3}$ for the mean $\mathrm{PM}_{10}$ between the scenario and the base case and on the right panel the same data are plot in relative terms. The figure regards the scenario 1 , hence a $50 \%$ reduction for the road transport emissions within the nested domain. 

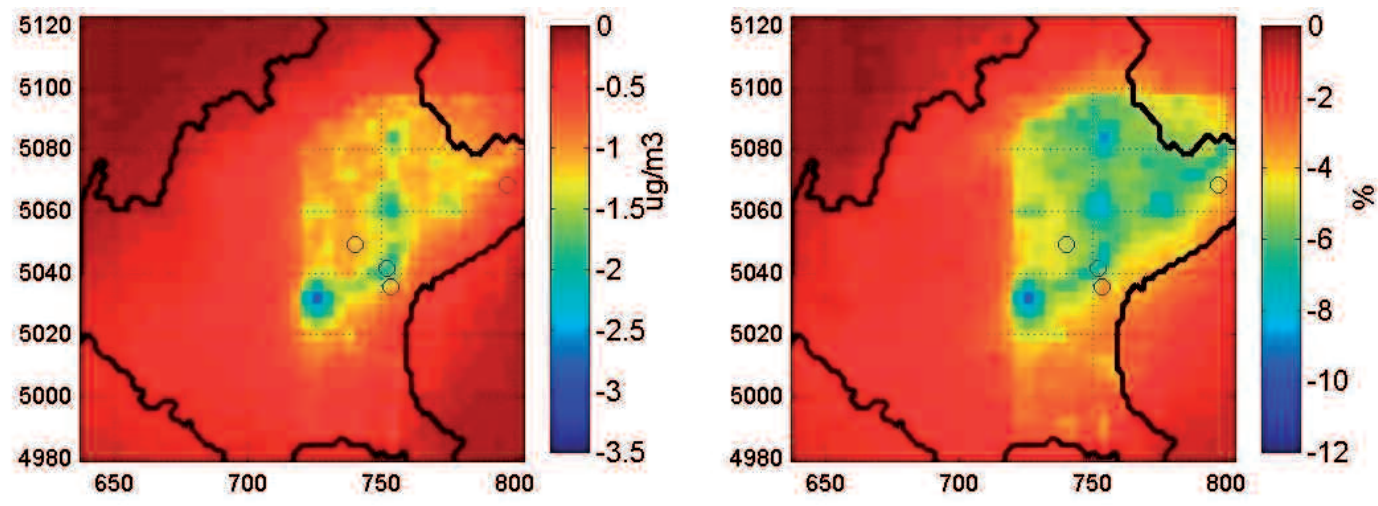

Figure 3. Absolute (left) and relative (right) reduction of average $\mathrm{PM}_{10}$ of the whole 2-months period for the road transport reduction scenario. Circles represents the fours sites: rural site to the north-east, industrial site to the south, curd-side site to the west and the urban site between the industrial and the curb-side sites.

As regard to the second result, the source apportionment analysis estimates that reducing by $50 \%$ the $10 c a l$ emissions (within the nested area) causes a reduction in $\mathrm{PM}_{10}$ concentrations (accounting both the $\mathrm{PM}_{10}$ generated both inside and outside nested area) in the following proportions:

$\checkmark$ scenario 1 (road transport): $3 \%$ both in the rural and industrial site, $4 \%$ at the urban curb-side and $7 \%$ in the urban site;

$\checkmark$ scenario 2 (industrial emissions): $2 \%$ in the rural site, $5 \%$ at the urban curb-side, $9 \%$ in the urban site and $11 \%$ in the industrial site;

$\checkmark$ scenario 3 (other transport emissions - airport, port and off road transports): $1 \%$ in the rural site, $2 \%$ at the urban curb-side, $3 \%$ in the urban site and $7 \%$ in the industrial site. The harbour, which is the main off road source for this sector and which is located nearer the industrial site then the urban site, has only a local impact: its weight is in fact greater in the industrial site then in the urban one;

$\checkmark$ scenario 4 (domestic heating): $2 \%$ in the rural site, $4 \%$ at the urban curb-side, $2 \%$ in the urban site and $1 \%$ in the industrial site. This low weight for the domestic heating is probably due to the large use of natural gas, which is compulsory according to the protecting heritage law for Venice;

$\checkmark$ scenario 5 (agriculture): $5 \%$ in the rural site, 3\% at the urban curb-side, $1 \%$ both in the urban site and in the industrial one. In the rural site the main sector is clearly agriculture that, with its $50 \%$ of emissions gives about $9 \%$ of nitrates. In the middle town inside the country, where the model simulates a mixing area of urban and rural plumes, the agriculture's weight is greater then in the industrial and urban area of Mestre.

The above percentages are small and translates in reduction from a few tenths to a few units of micrograms per cubic meters of $\mathrm{PM}_{10}$. The average $\mathrm{PM}_{10}$ level estimated by the model is around $17 \mu \mathrm{gm}^{-3}$ at the rural site and between 27 and $31 \mathrm{\mu gm}^{-3}$ in the other sites. If however we consider only the local $\mathrm{PM}_{10}$ levels (last column of Tab. 2) the relative percentages modifies as in Table 3 .

Table 3. Source apportionment for local $\mathrm{PM}_{10}$.

\begin{tabular}{|l|r|r|r|r|}
\cline { 2 - 5 } \multicolumn{1}{c|}{} & \multicolumn{4}{c|}{ Site } \\
\hline \multicolumn{1}{c|}{ Scenarios } & Rural background & Urban curb-side & Urban & Industrial \\
\hline 1. Road Transports & $24 \%$ & $26 \%$ & $29 \%$ & $14 \%$ \\
\hline 2. Industrial Plants & $13 \%$ & $29 \%$ & $41 \%$ & $44 \%$ \\
\hline 3. Other Transports & $8 \%$ & $9 \%$ & $15 \%$ & $6 \%$ \\
\hline 4. Domestic Heating & $15 \%$ & $20 \%$ & $9 \%$ & $5 \%$ \\
\hline 5. Agriculture & $40 \%$ & $16 \%$ & $5 \%$ & $5 \%$ \\
\hline
\end{tabular}

The source apportionment depends on the location of the site and the emission sector; for example road transport has a maximum weight of $26 \%$ in the urban-exposed site and a minimum value of $14 \%$ in the industrial site, while industrial plants has a maximum of $44 \%$ in the industrial site and a minimum of $13 \%$ in the rural background one.

\section{CONCLUSIONS}

The conclusions of the multi-scenario runs of the CALMET-CAMx modelling system on the wide urban area of Venice and its mainland are:

1. daily mean measures of $\mathrm{PM}_{10}$ concentrations are well reproduced by the modelling system for clean days (days during and following a thunderstorms), but model underestimates $\mathrm{PM}_{10}$ levels in the days with stagnant air conditions and the underestimation becomes stronger as the stagnant conditions persist (Fig. 1); 
2. secondary inorganic aerosol production proved to be well described by the model; organic aerosol (mainly secondary but also trans-boundary primary transport) is underestimated (Fig. 2) or not modelled (eg. resuspension);

3. the average $\mathrm{PM}_{10}$ level estimated by the model is around $17 \mu \mathrm{gm}^{-3}$ at the rural site and between 27 and 31 ${\mu \mathrm{gm}^{-3}}^{-3}$ in the other sites. The average scenarios impact vary between few tenths to few units of micrograms per cubic metre;

4. in the hypothesis that the emission perturbations had not changed significantly the atmospheric composition and reactivity, the local anthropogenic emission contribution to the average $\mathrm{PM}_{10}$ levels has been estimated. The local emissions contribution to the $\mathrm{PM}_{10}$ varies between 30 and 50\% (Tab. 2, last column). However we need to keep in mind that the model capture only part of PM in the area under investigation, which, at worst, is about half of the measured value (Fig. 1);

5. taking into account only locally produced $\mathrm{PM}_{10}$, a source apportionment analysis has been performed by calculating the differences in concentrations of each scenario and the base case (Fig. 3 and Tab. 3). The traffic emission contributes roughly $26-29 \%$ of the locally produced PM10 at curb-side or in a rural background site. Agriculture emission contributes $40 \%$ in a rural site and Industrial emissions accounts for $44 \%$ of the local portion of $\mathrm{PM}_{10}$ in an industrial site. These estimates do not account for the $\mathrm{PM}_{10}$ concentrations coming from outside the Venice area (nested domain);

6. the changes in $\mathrm{PM}_{10}$ concentrations resulting from the emission source perturbations are always less severe then the source perturbation itself. Inorganic secondary components of the aerosol are more resilient then primary ones; however the reduction of the local anthropogenic primary aerosol is not sufficient to turn down significantly $\mathrm{PM}_{10}$ concentration levels.

\section{REFERENCES}

Benassi, A., F. Dalan, A. Gnocchi, G. Maffeis, G. Malvasi, F. Liguori, D. Pernigotti, S. Pillon, M. Sansone, and L. Susanetti, 2007: The Veneto region modelling system for air quality assessment, $11^{\text {th }}$ International Conference on Harmonisation within Atmospheric Dispersion Modelling for Regulatory Purposes, Cambridge, 2 -5 July 2007.

Biancotto, R., M. Piovesan, S. Pistollato, M. Rosa and C. Zemello, 2007: Studio pilota sulla caratterizzazione del PM10 in provincia di Venezia. Dicembre 2007. http://www.arpa.veneto.it/dapve/docs/Studio_pilota_PM10_VE_dic2007.pdf

Dalan, F., S. Pillon, G. Maffeis, F. Liguori and A. Benassi, 2005: Validation and source apportionment analyses of CAMx model over the Veneto Region and Venice Lagoon. $10^{\text {th }}$ International Conference on "Harmonisation within Atmospheric Dispersion Modelling for Regulatory Purposes, Sissi, Crete, October 17-20, 2005.

ENVIRON International Corporation, 2004: Comprehensive Air Quality Model with extensions (CAMx), versione 4.03 ENVIRON International Corporation, USA (http://www.camx.com).

Gnocchi, A., G. Maffeis, G. Malvasi, L. Susanetti, K. Lorenzet and A. Benassi, 2005: An integrated top-down and bottom-up approach to estimate atmospheric emissions in the Venice Lagoon. ${ }^{\text {st }}$ International Conference on Harbours \& Air Quality, Genoa (Italy), 15-17 June 2005.

Gnocchi, A., G. Malvasi, G. Maffeis, K. Lorenzet, L. Susanetti and A. Benassi, 2006: Stima delle emissioni in atmosfera nella laguna di Venezia secondo un approccio integrato Top-Down e Bottom-Up. Ingegneria Ambientale, 7/8, 359-368.

Pillon, S., F. Dalan, G. Maffeis, F. Liguori and A. Benassi, 2007: Applicazione modello fotochimico CAMx: caso di studio PM10 nel periodo febbraio-marzo 2006 e analisi del contributo locale in area veneziana. Maggio 2007. http://www.arpa.veneto.it/dapve/docs/Applicazione_CAMx_PM10_relazione_ORAR.pdf

Scire, J. S., F. R. Robe, M. E. Fernau and R. J. Yamartino, 2000: A user's guide for the CALMET Meteorological Model. Earth Tech., USA.

Wagstrom, K. M., S. N. Pandis, G. Yarwood, G. M. Wilson and R. E. Morris, 2008: Development and application of a computationally efficient particulate matter apportionment algorithm in a three-dimensional chemical transport model. Atmospheric Environment, 42, 5650- 5659. 